\title{
Is there a relation between onset age of bilingualism and enhancement of cognitive control?
}

\section{Citation}

LUK, GIGI, ERIC DE SA, and ELLEN BIALYSTOK. 2011. "Is there a relation between onset age of bilingualism and enhancement of cognitive control?" Bilingualism: Language and Cognition 14 (04) (October 4): 588-595. doi:10.1017/S1366728911000010. http://dx.doi.org/10.1017/ S1366728911000010.

\section{Published Version}

doi:10.1017/S1366728911000010

\section{Permanent link}

http://nrs.harvard.edu/urn-3:HUL.InstRepos:11384946

\section{Terms of Use}

This article was downloaded from Harvard University's DASH repository, and is made available under the terms and conditions applicable to Open Access Policy Articles, as set forth at http:// nrs.harvard.edu/urn-3:HUL.InstRepos:dash.current.terms-of-use\#OAP

\section{Share Your Story}

The Harvard community has made this article openly available.

Please share how this access benefits you. Submit a story.

Accessibility 


\section{Bilingualism: Language and Cognition}

http://journals.cambridge.org/BIL

Additional services for Bilingualism: Language and Cognition:

Email alerts: $\underline{\text { Click here }}$

Subscriptions: Click here

Commercial reprints: $\underline{\text { Click here }}$

Terms of use : $\underline{\text { Click here }}$

\section{Is there a relation between onset age of bilingualism and enhancement of cognitive control?}

GIGI LUK, ERIC DE SA and ELLEN BIALYSTOK

Bilingualism: Language and Cognition / Volume 14 / Issue 04 / October 2011, pp 588 - 595

DOI: 10.1017/S1366728911000010, Published online: 04 March 2011

Link to this article: http://journals.cambridge.org/abstract_S1366728911000010

How to cite this article:

GIGI LUK, ERIC DE SA and ELLEN BIALYSTOK (2011). Is there a relation between onset age of bilingualism and enhancement of cognitive control?. Bilingualism: Language and Cognition, 14, pp 588-595 doi:10.1017/

S1366728911000010

Request Permissions : $\underline{\text { Click here }}$ 


\section{Is there a relation between onset age of bilingualism and enhancement of cognitive control?*}

\author{
GIG I LUK \\ Rotman Research Institute at Baycrest \\ ERIC DE SA \\ York University \\ ELLEN BIALYSTOK \\ Rotman Research Institute at Baycrest \& York University
}

(Received: May 14, 2010; final revision received: January 4, 2011; accepted: January 5, 2011; First published online 4 March 2011)

Young English-speaking monolingual and bilingual adults were examined for English proficiency, language use history, and performance on a flanker task. The bilinguals, who were about twenty years old, were divided into two groups (early bilinguals and late bilinguals) according to whether they became actively bilingual before or after the age of ten years. Early bilinguals and monolinguals demonstrated similar levels of English proficiency, and both groups were more proficient in English than late bilinguals. In contrast, early bilinguals produced the smallest response time cost for incongruent trials (flanker effect) with no difference between monolinguals and late bilinguals. Moreover, across the whole sample of bilinguals, onset age of active bilingualism was negatively correlated with English proficiency and positively correlated with the flanker effect. These results suggest a gradient in which more experience in being actively bilingual is associated with greater advantages in cognitive control and higher language proficiency.

Keywords: bilingualism, age of acquisition, cognitive control, vocabulary size

Recent research reporting a positive influence of bilingualism on executive control (for review, see Bialystok, 2007) leaves unanswered the question of how much bilingual experience is needed to enjoy these benefits. Typically, the research selects bilingual participants who are very fluent in two languages and use both regularly. This classification of bilingualism is generally based on an assessment of such factors as onset age of second language (L2) acquisition, proficiency in the second language, and length of exposure to the L2. Although these variables concerning bilingual history have been shown to influence aspects of language and literacy development (Kovelman, Baker \& Petitto, 2008; Sundara, Polka \& Genesse, 2006; Uccelli \& Páez, 2007), their role in determining the relation between bilingualism and cognitive outcomes is unknown.

The usual explanation for the bilingual effect on executive control is that bilinguals need to manage attention to two available systems and therefore recruit the executive control network for this purpose (e.g., Abutalebi \& Green, 2007). The constant involvement of this executive control system in managing attention to two languages fortifies that system, resulting in earlier development in children and more effective functioning in adulthood. For example, bilingual children and adults

\footnotetext{
* This work was partially supported by grant R01HD052523 from the US National Institutes of Health and by grant A2559 from the Natural Sciences and Engineering Research Council of Canada to EB.
}

perform better than their monolingual peers in tasks that require cognitive flexibility (e.g., dimensional cardsorting task for children and adults, Bialystok, Craik \& Ruocco, 2006; Bialystok \& Martin, 2004) and inhibition of distracting or conflicting information (e.g., appearance-reality resolution in children, Bialystok \& Shapero, 2005; Simon task in children and older adults, Bialystok, Craik, Klein \& Viswanathan, 2004; MartinRhee \& Bialystok, 2008; behavioural antisaccade task in young and older adults, Bialystok, Craik \& Ryan, 2006; Bialystok \& Viswanathan, 2009; and flanker task in young and middle-aged adults, Costa, Hernández \& SebastiánGallés, 2008; Emmorey, Luk, Pyers \& Bialystok, 2008). In all these studies, bilinguals were selected to be individuals who had used both their languages to a high degree of proficiency for most of their lives. A summary of the demographic information related to bilingual performance is reported in Table 1 (for a recent review on cognitive advantages in bilinguals, see Adesope, Lavin, Thompson \& Ungerleider, 2010). The question for the present study is whether there is a relation between the onset age of this experience and the magnitude of the effect found in bilingual performance.

In addition to modifying cognitive performance, bilingualism has also been shown to alter brain structures. Mechelli et al. (2004) found that increased grey matter density in the left inferior parietal area was positively related to bilinguals' L2 proficiency and negatively related to age of L2 acquisition. In other words, greater

Address for correspondence:

Gigi Luk, Rotman Research Institute, Baycrest Centre, 3560 Bathurst Street, Toronto, Ontario, M6A 2E1 Canada

gluk@rotman-baycrest.on.ca 
Table 1. Summary of studies reporting a bilingual advantage in cognitive tasks indicating age of participants, age of onset of bilingualism (L2A), and length of bilingual experience.

\begin{tabular}{|c|c|c|c|c|c|c|c|}
\hline No. & Authors & Year & $\begin{array}{l}\text { Bilingual } \\
\text { sample } \\
\text { size }\end{array}$ & Age & $\begin{array}{l}\text { L2A } \\
\text { onset } \\
\text { age }\end{array}$ & $\begin{array}{l}\text { Onset } \\
\text { of active } \\
\text { bilingualism }\end{array}$ & Task \\
\hline \multirow[t]{5}{*}{1} & Bialystok, Craik, Klein \& Viswanathan & 2004 & & & & & \\
\hline & (study 1) & & 10 & 43 & 6 & - & Simon task \\
\hline & & & 10 & 71 & 6 & - & Simon task \\
\hline & (study 2) & & 32 & 42 & 6 & - & Simon task with working memory \\
\hline & & & 15 & 70 & 6 & - & Simon task with working memory \\
\hline \multirow[t]{3}{*}{2} & Bialystok \& Martin & 2004 & & & & & \\
\hline & (study 1) & & 31 & 4.9 & - & - & Dimensional card sorting task \\
\hline & (study 2) & & 15 & 4.5 & birth & birth & Dimensional card sorting task \\
\hline \multirow[t]{3}{*}{3} & Bialystok \& Shapero & 2005 & & & & & \\
\hline & (study 1) & & 24 & 6 & - & birth & Ambiguous figures \\
\hline & (study 2) & & 26 & 5.5 & - & birth & $\begin{array}{l}\text { Computerized dimensional } \\
\text { change card sort }\end{array}$ \\
\hline \multirow[t]{3}{*}{4} & Bialystok, Craik \& Ruocco & 2006 & & & & & \\
\hline & (study 1) & & 24 & 21 & - & 6 & Dual-modality classification \\
\hline & (study 2) & & 24 & 63 & - & 10 & Dual-modality classification \\
\hline \multirow[t]{3}{*}{5} & Bialystok, Craik \& Ryan & 2006 & & & & & \\
\hline & (study 2) & & 24 & 23 & - & 6 & Antisaccade task \\
\hline & & & 24 & 64 & - & 12 & Antisaccade task \\
\hline 6 & Costa, Hernandez \& Sebastian-Galles & 2008 & 100 & 22 & birth & birth & Attention network task \\
\hline 7 & Emmorey, Luk, Pyers \& Bialystok & 2008 & 15 & 47 & 6 & - & Flanker task \\
\hline \multirow[t]{3}{*}{8} & Martin-Rhee \& Bialystok & 2008 & & & & & \\
\hline & (study 1) & & 17 & 5 & birth & birth & Simon task \\
\hline & (study 2) & & 21 & 4.6 & birth & birth & Simon task \\
\hline \multirow[t]{2}{*}{9} & Bialystok \& Viswanathan & 2009 & 30 & 8.5 & birth & birth & Antisaccade task \\
\hline & & & 30 & 8.6 & birth & birth & Antisaccade task \\
\hline
\end{tabular}

modification was associated with longer and more proficient use of an L2. This brain area is recruited for various executive functions, such as focused and divided attention (Nebel, Wiese, Stude, de Greiff, Diener \& Keidel, 2005), category switching during word production (Gurd et al., 2002) and auditory sentence comprehension (Yeatman, Ben-Shachar, Glover \& Feldman, 2010). These cognitive processes have also been shown to be related to bilingual switching between languages in neuroimaging research (Abutalebi, Brambati, Annoni, Moro, Cappa \& Perani, 2007; Wang, Xue, Chen, Xue \& Dong, 2007). These findings indicate that handling two languages recruits a general cognitive control mechanism that is not specific to language processing. Therefore, if duration of bilingual experience results in structural changes in brain areas that are recruited for executive functions, then it is possible that different levels of executive function performance for bilinguals are also related to the degree of experience in handling two languages.

The present study compared monolinguals with bilinguals who started early or late in actively using two languages for their performance on an executive control task. The onset age of bilingualism was defined as the age at which the bilinguals began using both languages on a daily basis. This is different from other studies that use age of L2 acquisition or immigration age as the onset measure of bilingualism (see review in Birdsong, 2005). In other words, irrespective of the age at which a second language was learned, the present study evaluated 
the age at which that language became an active part of the individual's linguistic repertoire. An earlier onset age of active bilingualism also indicates longer history of using two languages in a sample of young adults. The bilingual young adults with an earlier onset age of active bilingualism were expected to perform better on an executive control task than monolinguals and bilinguals who started using two languages later in life. The cut-off age for categorizing bilinguals as early or late was chosen to be 10 years old. Previous research reporting support for a critical hypothesis suggested this period was around the age of puberty (e.g., Johnson \& Newport, 1989; DeKeyser, 2000). Since the sample in the present study was young adults around the age of 20, age 10 is slightly before puberty and divides bilinguals into those who have used two languages essentially for all their lives or half of their lives.

\section{Method}

\section{Participants}

One hundred and fifty-seven university students in a large multicultural city in Canada were recruited as participants in a large-scale project on profiles of bilingualism and executive control. Based on responses to a detailed language history questionnaire, participants were categorized as monolinguals, early bilinguals, or late bilinguals. Monolinguals reported that English was the only language that they spoke fluently and used for communication. All the bilinguals were asked to report the age at which they began using both languages actively and regularly on a daily basis. The reporting age was considered to be the onset age of active bilingualism. Early bilinguals reported that they started active bilingualism before the age of 10, and late bilinguals reported that their onset age of active bilingualism was after the age of 10 . Twenty-eight bilingual participants were excluded from the analysis because they had never used both languages actively in their daily lives, and six bilingual participants were excluded from the analyses that directly compared the two bilingual groups because they started to use two languages actively at the age of 10 so did not fit into either group. The 28 bilinguals who reported no everyday bilingual experience might represent a different group, possibly more similar to individuals attending English as a second language (ESL) programs. Therefore, this group was more heterogeneous than the other groups. The final sample consisted of 123 participants, with 38 monolinguals ( 9 males), 43 early bilinguals ( 5 males) and 42 late bilinguals (12 males). A chi-square test showed that the gender distribution was similar across groups, $\chi^{2}(2)=$ $3.6, n s$. The early bilinguals began active bilingualism at the age of five while the late bilinguals had the mean onset age of active bilingualism at 15 (see Table 2). In addition to onset age of active bilingualism, bilinguals also reported their onset age of L2 acquisition in formal (school or classroom) and informal (family and community) settings. Since not all the bilinguals had the experience acquiring L2 in a formal or informal setting, the number of positive responses is noted in the table.

The early and late bilingual participants spoke a large variety of languages in addition to English: Cantonese (early: 10 participants, late: 8 participants), French (early: 5, late: 5), Korean (early: 4, late: 2), Hebrew (early: 2, late: 3), Hindi (early: 2, late: 3), Italian (early: 3, late: 2), Mandarin (early: 1, late: 3), Farsi (early: 1, late: 2), Russian (late: 3), Tamil (early: 2, late: 1), Urdu (early: 2, late: 1), Spanish (early: 1, late: 2), Polish (early: 2), Punjabi (early: 1, late: 1), Vietnamese (early: 1, late: 1), and some languages were spoken by just one of the bilingual speakers: Marathi (early), Indonesian (late), Portuguese (early), Japanese (late), Gujarati (early), Toisan (early), Twi (early), Turkish (late), Ukrainian (late), Swahili (early), and Bulgarian (late). For the early bilinguals, 47\% reported that they were born outside Canada and had been living in Canada for about 12.7 years $(S D=6.1)$; for the late bilinguals, $79 \%$ reported other countries to be their birthplaces, and had lived in Canada for 6.1 years

Table 2. Means and standard deviations for background measures by group.

\begin{tabular}{|c|c|c|c|c|c|c|c|c|}
\hline Group & $\mathrm{N}$ & Age & $\begin{array}{l}\text { Age of } \\
\text { active } \\
\text { bilingualism }\end{array}$ & $\begin{array}{l}\text { Age of } \\
\text { formal L2 } \\
\text { acquisition }^{\text {a }}\end{array}$ & $\begin{array}{l}\text { Age of } \\
\text { informal L2 } \\
\text { acquisition }^{\text {b }}\end{array}$ & CFIT $^{\mathrm{c}, \mathrm{d}}$ & $\begin{array}{l}\text { Spatial } \\
\text { span }^{\mathrm{b}}\end{array}$ & $\begin{array}{l}\text { English } \\
\text { PPVT-III }\end{array}$ \\
\hline Early bilinguals & 43 & $21.1(2.1)$ & $5.1(2.9)$ & $5.3(1.9)$ & $2.0(2.3)$ & $109.8(14.9)$ & $9.7(2.3)$ & $101.6(10.5)$ \\
\hline Late bilinguals & 42 & $21.3(2.4)$ & $15.9(3.5)$ & $9.1(3.8)$ & $6.1(4.8)$ & $110.9(15.6)$ & $9.1(2.6)$ & $90.2(15.6)$ \\
\hline Monolinguals & 38 & $21.0(1.8)$ & - & - & - & $112.7(12.4)$ & $9.2(2.6)$ & $102.5(10.1)$ \\
\hline
\end{tabular}

\footnotetext{
${ }^{a}$ Thirty-nine early bilinguals and 40 late bilinguals reported that they had formally acquired L2 in a classroom or other school setting.

b Twenty-nine early bilinguals and 20 late bilinguals reported that they had informally acquired L2 at home or in community.

${ }^{\mathrm{c}}$ Cattell Culture Fair Intelligence Test

${ }^{\mathrm{d}}$ Table entries are standardized scores controlling for age.
} 
$(S D=4.4)$. A proportion $(21 \%)$ of monolinguals was born outside Canada in other English-speaking countries.

The bilinguals were asked to indicate the proportion of use of each of their two languages in different contexts on a visual analog scale that was $10 \mathrm{~cm}$ long. The left end of the scale was marked as "No English" and the right end as "All English". Participants drew a line marking the point on the scale indicating the balance between the two languages for that activity. For work/school contexts, the early bilinguals $(M=9.0, S D=1.7)$ and late bilinguals $(M=8.4, S D=2.1)$ reported equivalently high usage of English, $t(84)=1.5$, ns. However, the early bilinguals reported higher usage of English at home $(M=6.7$, $S D=2.7)$ than late bilinguals $(M=4.9, S D=3.3)$, $t(84)=2.8, p<.01$. Thus, both bilingual groups had English as their dominant language in the community but the early bilinguals used more English at home than the late bilinguals. In addition, the bilingual participants were asked to rate their language proficiency relative to a native speaker in their first language (L1) and L2, respectively. The early bilinguals reported a slightly more balanced ratings for their $\mathrm{L} 1(\mathrm{M}=8.8, S D=1.5)$ and $\mathrm{L} 2(\mathrm{M}=$ 7.6, $S D=2.3$ ) while the late bilinguals reported slightly higher $\mathrm{L} 1$ proficiency $(\mathrm{M}=9.1, S D=1.5)$ compared to their $\mathrm{L} 2$ proficiency $(\mathrm{M}=6.7, S D=2.2)$. A two-way group by L1/L2 ANOVA showed no significant overall proficiency ratings difference between groups, $F=1$, $\mathrm{MSE}=3, n s$; a significantly higher L1 rating compared to $\mathrm{L} 2$ in all groups, $F(1,83)=135$, $\mathrm{MSE}=4.2, p<.0001$; and a marginally significant group by $\mathrm{L} 1 / \mathrm{L} 2$ interaction, $F(1,83)=14$, MSE $=4.2, p=.06$, suggesting a larger difference between ratings in L1 and L2 in late bilinguals than in early bilinguals.

\section{Tasks}

Three standardized tasks were administered. The Peabody Picture Vocabulary Task 3rd edition (PPVT-III; Dunn $\&$ Dunn, 1997) was used to assess receptive vocabulary, the Cattell Cultural Fair Intelligence Test (CFIT; Cattell, 1957) to assess nonverbal intelligence, and the Spatial Span Subtest from the Wechsler Memory Scale 3rd edition (WMS-III; Wechsler, 1997) to assess spatial working memory. All these tasks were administered according to the standard procedures indicated in the manuals.

\section{Flanker task}

The flanker task was adapted from Eriksen and Eriksen (1974) and Bunge, Dudukovic, Thomason, Vaidya and Gabrieli (2002). Participants were asked to indicate the direction of a red chevron flanked by black distractor chevrons by pressing either the left or the right mouse button located on each side of the monitor. Sample

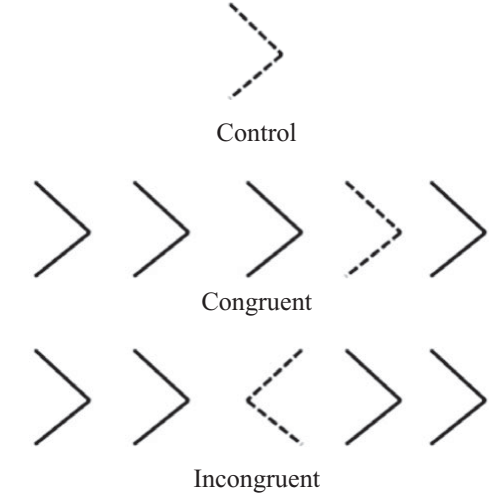

Figure 1. Sample stimuli in the flanker task.

stimuli are presented in Figure 1 (red chevron is presented in dashed line instead of red ink). In control trials to assess baseline response time (RT), only one red chevron pointing left or right was presented in the center of the screen. In congruent trials, there was an array of five chevrons all pointing in the same direction, and in incongruent trials the flanking chevrons pointed in the opposite direction. The red target chevron could appear in any one of the three central positions in the array. Successful response required the recruitment of executive control to focus on the target chevron and avoid being distracted by the irrelevant conflicting flankers.

Each block began with 12 practice trials. All participants were given the choice of receiving more practice if they wished, but none of them made this request. Each trial began with $500 \mathrm{~ms}$ fixation, followed by the stimulus which was presented for $2000 \mathrm{~ms}$ or until the participant responded. There were two control blocks containing 12 trials each and two conflict blocks each containing 24 congruent and 24 incongruent trials. Trials within each block were presented randomly and were counterbalanced for direction of the target arrow and type of trial. Both RT and accuracy were measured, but only trials associated with a correct response were included in the RT analysis.

\section{Results}

The descriptive statistics for each group on the background measures are presented in Table 2 (above). There were no group differences in age, CFIT, or spatial span, $F \mathrm{~s}<1$. The three groups differed in PPVT-III scores, $F(2,120)=12.8$, MSE $=153.5, p<.0001$, with late bilinguals attaining a lower score than the early bilinguals and the monolinguals who were not different from each other. All participants achieved high accuracy rates in the flanker task, ranging from .96 to 1 . With the limited variability in accuracy rates, no statistical comparison was conducted. 
Table 3. Mean response times and standard deviations for correct trials in the three conditions of the flanker task.

\begin{tabular}{llll}
\hline \hline \multirow{2}{*}{ Group } & \multicolumn{3}{c}{ Flanker task } \\
\cline { 2 - 4 } & Control & Congruent & Incongruent \\
\hline Early bilinguals & $415.8(76.4)$ & $513.4(83.3)$ & $557.9(80.9)$ \\
Late bilinguals & $405.7(53.3)$ & $509.7(89.7)$ & $569.8(87.2)$ \\
Monolinguals & $397.4(51.5)$ & $503.4(61.4)$ & $565.2(70.3)$ \\
\hline \hline
\end{tabular}

The descriptive statistics for the RT in the flanker task are reported in Table 3. A one-way ANOVA for group was conducted on the control blocks and showed no difference, $F(2,120)<1$. A two-way group $(3) \times$ trial type (2) ANOVA was carried out for the conflict blocks. There was no overall group difference, $F<1$, but a significant trial type effect, $F(1,120)=419.8, \mathrm{MSE}=$ $449.9, p<.0001$, and trial type by group interaction, $F(2,120)=4.2, \mathrm{MSE}=449.9, p<.02$. Nonetheless, simple ANOVAs conducted separately by group showed that the trial type effect was similar for all three groups in that congruent trials were faster than incongruent trials, $F \mathrm{~s}>315, p<.0001$, and there were no significant group differences on either congruent or incongruent trials, $F \mathrm{~s}<1$.

To calculate the efficiency of executive control and take into account individual differences in RT, three RT costs were calculated (see Figure 2). First, the RT difference between congruent and control trials indicated the additional time required for processing visual search for the target in face of non-conflicting flankers. Oneway ANOVA revealed no group difference in this measure, $F<1$. Second, the RT difference between incongruent and control trials was calculated to represent the additional processing time needed for resolving conflicting distractors as well as making a visual search. A significant group difference was observed, $F(2,121)=$ 4.22, MSE $=1901.7, p<.02$, with the early bilinguals showing the smallest costs $(M=142.1)$, and the late bilinguals $(M=164.1)$ and monolinguals $(M=167.8)$ not differing from each other in Fisher's least significant difference (LSD) test. Finally, the RT difference between congruent and incongruent trials, or flanker effect, indicated the additional processing time needed for resolving conflict after taking into account visual search shifting costs from switching between congruent and incongruent trials. Again, there was a significant group difference, $F(2,121)=4.22$, MSE $=899.8, p<.02$, with the early bilinguals showing the smallest cost $(\mathrm{M}=44.5)$ and the late bilinguals $(M=60.2)$ and monolinguals $(M=$ 61.8) not different from each other.

Finally, we examined whether there was a relationship between the onset age of bilingualism, PPVT-III scores, and the three cost variables for the whole sample of 91 bilingual participants (including the six bilinguals who reported their onset age of active bilingualism was 10 years). All the variables were inspected to ensure that their distributions were approximately normal. The distributions for PPVT-III and the three cost measures approached normality while the onset age of active bilingualism violated the assumption because 19 people reported 0 as onset age. Therefore, the onset age of active bilingualism was transformed with logarithm to base 10 . In this case, the " 0 " responses were converted to missing values and the distributions approached normality. Onset age of active bilingualism correlated negatively with English receptive vocabulary, measured by PPVT-III, $r(84)=-.42, p<.0001$. The inverse relationship suggests that earlier onset of active bilingualism is associated with higher performance in English receptive vocabulary. In contrast, onset age of active bilingualism correlated positively with the flanker effect, $r(84)=.24, p<.03$, indicating a smaller flanker effect for those who had been actively bilingual for a longer period of time. There was no significant correlation between onset age of active bilingualism and the other cost variables. Figure 3 presents the overlaying scatterplots of the correlations between onset age of active bilingualism, PPVT-III, and the flanker effect. The correlation analysis was also carried with the untransformed onset age for active bilingualism; a slightly weaker but significant correlation remained, $r(84)=$ $.22, p<.05$. To further confirm that onset age of active bilingualism was a sensitive measure relative to other onset age variables, the flanker effect was also correlated with log-transformed onset age of formal and informal L2 acquisition. There was no correlation between age of L2 acquisition with PPVT or the flanker effect either in the formal (school, classroom), rs $(85)<.1, n s$, or informal settings (home, community), rs $(34)<.2, n s$.

\section{Discussion}

Replicating previous research, bilinguals who had been actively using two languages for most of their lives showed less interference on a flanker task than did comparable monolinguals. The novel finding in the present study is that participants who were less bilingual in that they had been using two languages for only about half of their lives performed more like monolinguals on the executive control task. These participants, not surprisingly, also had significantly lower scores in English proficiency, their L2. These group comparisons provide evidence for the view that there is a relation between the onset age of actively practicing bilingualism and the size of the effects typically reported in the literature. In this case, the effect of bilingualism on executive control emerges through the experience of using two languages, with earlier and continuing experience conferring larger effects. Confirming this interpretation, a correlation 


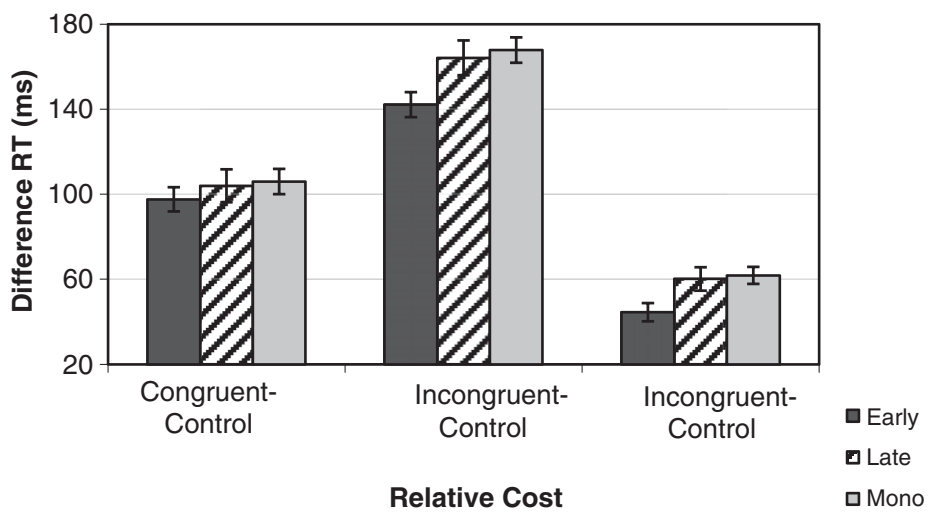

Figure 2. Mean RT costs for congruent and incongruent trials in conflict block relative to control trials and the flanker effect (Incongruent-Congruent) by language group.

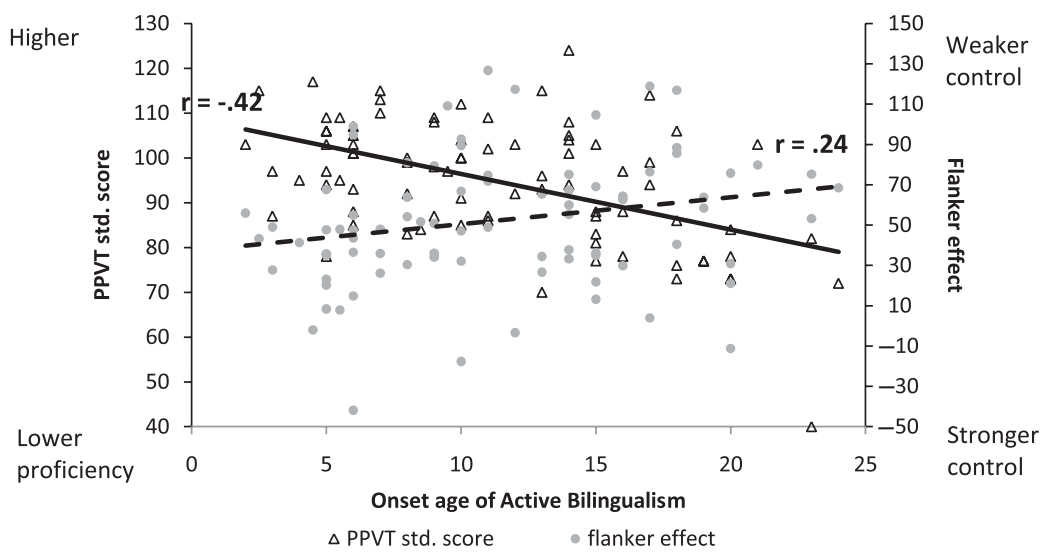

Figure 3. Overlayed scatterplots of correlations between onset age of active bilingualism and PPVT-III standard scores and flanker effect.

analysis conducted on the full sample of nearly 100 participants indicated a positive relation between the onset age that the individual had been actively bilingual and the size of the bilingual effects on performance.

It is inevitable that the early bilinguals also became proficient in their L2 at an earlier age than the late bilinguals, confounding length of time being bilingual and age of acquisition of a second language. If the relevant variable is length of time, then any extended period of using two languages through the lifespan should lead to these effects; if the relevant variable is age of L2 acquisition, then there may be a critical period for becoming bilingual in which these executive control advantages are found only before the close of that period. There is no means of accurately disentangling these factors in a sample of young adults because equivalent and sufficient duration of bilingualism (for example, 10 years) cannot be interspersed with different ages of becoming bilingual, although an older sample may provide the opportunity to test these effects separately. In our view, both the continuity of the bilingual experience over an extended period of time and an early age of becoming bilingual contribute to the emergence of the outcomes on cognitive control. Thus, there is no evidence for a critical period that categorically determines the presence or absence of these outcomes. Our description of the combination of age and duration is in the concept "age of active bilingualism".

Two results support this interpretation. First, the correlation between age of becoming actively bilingual and English proficiency is consistent with a large-scale study of over two million participants reported by Hakuta, Bialystok and Wiley (2003) in which increased age of L2 acquisition was associated with decreased L2 proficiency across the lifespan. There was no evidence of an effect of a critical period in that study. Second, if the relevant variable were age of $\mathrm{L} 2$ acquisition and a critical period was observed, then beyond this putative critical period, there should NOT be a correlation with bilingual performance. However, the correlation analysis conducted on the whole sample showed a continual relation in which earlier and continuing bilingual experience was associated with stronger effects, as shown in Figure 3. Again, there was no indication of a critical period. The 
results instead support the interpretation that early and persistent bilingual experience is related to increased cognitive benefit and higher L2 proficiency.

Instead of age of immigration or onset age of L2 acquisition, both common measures in the literature (see Birdsong, 2005 for a review), we assessed bilingual participants' onset age of active bilingualism. This variable recorded the age at which each participant began using two languages actively on a daily basis. An individual may not immediately use two languages after immigration and certainly not immediately after beginning to learn a second language. Therefore, we believe that onset age of active bilingualism is a better representation of the age when bilingualism begins. Using the onset age of active bilingualism to categorize bilinguals into early and late groups showed that early bilinguals and monolinguals had similar levels of English proficiency, as measured by the PPVT, and both exceeded that of the late bilinguals. In addition, the early bilinguals were more efficient in suppressing conflicting information, as reflected by the smaller flanker effect. Subsequently, the correlation analysis confirmed that earlier emerging bilingualism, coupled with longer bilingual experience, leads to higher proficiency in that language and stronger cognitive control. These results substantiate previous research reporting a bilingual advantage by showing a linear relationship between onset age of active bilingualism with PPVT and flanker performance. Moreover, the onset age of active bilingualism was demonstrated to be a sensitive variable to an individual's beginning of bilingual history.

\section{References}

Abutalebi, J., Brambati, S. M., Annoni, J. M., Moro, A., Cappa, S. F., \& Perani, D. (2007). The neural cost of the auditory perception of language switches: An event-related functional magnetic resonance imaging study in bilinguals. Journal of Neuroscience, 27, 13762-13769.

Abutalebi, J., \& Green, D. (2007). Bilingual language production: The neurocognition of language representation and control. Journal of Neurolinguistics, 20, 242-275.

Adesope, O. O., Lavin, T., Thompson, T., \& Ungerleider, C. (2010). A systematic review and meta-analysis of the cognitive correlates of bilingualism. Review of Educational Research, 80, 207-245.

Bialystok, E. (2007). Cognitive effects of bilingualism: How linguistic experience leads to cognitive change. International Journal of Bilingual Education and Bilingualism, 10, 210-223.

Bialystok, E., Craik, F. I. M., Klein, R., \& Viswanathan, M. (2004). Bilingualism, aging, and cognitive control: Evidence from the Simon task. Psychology and Aging, 19, 290-303.

Bialystok, E., Craik, F. I. M., \& Ruocco, A. C. (2006). Dual modality monitoring in a classification task: The effects of bilingualism and aging. Quarterly Journal of Experimental Psychology (A), 59, 1968-1983.

Bialystok, E., Craik, F. I. M., \& Ryan, J. (2006). Executive control in a modified antisaccade task: Effects of aging and bilingualism. Journal of Experimental Psychology: Learning, Memory, and Cognition, 32, 1341-1354.

Bialystok, E., \& Martin, M. M. (2004). Attention and inhibition in bilingual children: Evidence from the dimensional change card sort task. Developmental Science, 7, 325-339.

Bialystok, E., \& Shapero, D. (2005). Ambiguous benefits: The effect of bilingualism on reversing ambiguous figures. Developmental Science, 8, 595-604.

Bialystok, E., \& Viswanathan, M. (2009). Components of executive control with advantages for bilingual children in two cultures. Cognition, 112, 494-500.

Birdsong, D. (2005). Interpreting age effects in second language acquisition. In J. F. Kroll \& A. M. B. de Groot (eds.), Handbook of bilingualism: Psycholinguistic approaches, pp. 109-127. New York: Oxford University Press.

Bunge, S. A., Dudukovic, N. M., Thomason, M. E., Vaidya, C. J., \& Gabrieli, J. D. (2002). Immature frontal lobe contributions to cognitive control in children: Evidence from fMRI. Neuron, 33, 301-311.

Cattell, R. B. (1957). Culture fair intelligence test, a measure of " $g$ ": Scale 3, forms A and B (high school pupils and adults of superior intelligence). Savoy, IL: Institute for Personality and Ability Testing.

Costa, A., Hernández, M., \& Sebastián-Gallés, N. (2008). Bilingualism aids conflict resolution: Evidence from the ANT task. Cognition, 106, 59-86.

DeKeyser, R. M. (2000). The robustness of critical period effects in second language acquisition. Studies in Second Language Acquisition, 22, 499-533.

Dunn, L. M., \& Dunn, L. M. (1997). Peabody Picture Vocabulary Test - Third Edition. Bloomington, IN: Pearson Assessments.

Emmorey, K., Luk, G., Pyers, J., \& Bialystok, E. (2008). The source of enhanced cognitive control in bilinguals: Evidence from bimodal bilinguals. Psychological Science, 19, 1201-1206.

Eriksen, B. A., \& Eriksen, C. W. (1974). Effects of noise letters upon the identification of a target letter in a nonsearch task. Perception \& Psychophysics, 16, 143149.

Gurd, J. M., Amunts, K., Weiss, P. H., Zafiris, O., Zilles, K., Marshall, J. C., \& Fink, G. R. (2002). Posterior parietal cortex is implicated in continuous switching between verbal fluency tasks: An fMRI study with clinical implications. Brain, 125, 1024-1038.

Hakuta, K., Bialystok, E., \& Wiley, E. (2003). Critical evidence: A test of the critical-period hypothesis for second-language acquisition. Psychological Science, 14, 31-38.

Johnson, J. S., \& Newport, E. L. (1989). Critical period effects in second language learning: The influence of the maturational state on the acquisition of English as a second language. Cognitive Psychology, 21, 60-99.

Kovelman, I., Baker, S. A., \& Petitto, L.-A. (2008). Age of first bilingual language exposure as a new window into bilingual reading development. Bilingualism: Language and Cognition, 11, 203-223. 
Martin-Rhee, M. M., \& Bialystok, E. (2008). The development of two types of inhibitory control in monolingual and bilingual children. Bilingualism: Language and Cognition, 11, 81-93.

Mechelli, A., Crinion, J. T., Noppeney, U., O’Doherty, J., Ashburner, J., Frackowiak, R. S., \& Price, C. J. (2004). Structural plasticity in the bilingual brain: Proficiency in a second language and age at acquisition affect grey-matter density. Nature, 431, 757.

Nebel, K., Wiese, H., Stude, P., de Greiff, A., Diener, H. C., \& Keidel, M. (2005). On the neural basis of focused and divided attention. Brain Research: Cognitive Brain Research, 25, 760-776.

Sundara, M., Polka, L., \& Genesee, F. (2006). Languageexperience facilitates discrimination of $/ \mathrm{d}-\mathrm{d} / \mathrm{in}$ monolingual and bilingual acquisition of English. Cognition, 100, 369-388.
Uccelli, P., \& Páez, M. M. (2007). Narrative and vocabulary development of bilingual children from kindergarten to first grade: Developmental changes and associations among English and Spanish skills. Language, Speech, and Hearing Services in Schools, 38, 225-236.

Wang, Y., Xue, G., Chen, C., Xue, F., \& Dong, Q. (2007). Neural bases of asymmetric language switching in secondlanguage learners: An ER-fMRI study. NeuroImage, 35, 862-870.

Wechsler, D. (1997). Spatial span subtest of Wechsler Memory Scale - Third Edition (WMS-III). San Antonio, TX: The Psychological Corporation.

Yeatman, J. D., Ben-Shachar, M., Glover, G. H., \& Feldman, H. M. (2010). Individual differences in auditory sentence comprehension in children: An exploratory event-related functional magnetic resonance imaging investigation. Brain and Language, 114, 72-79. 